\title{
A Knowledge Management Approach To Format The Financial World-Class Policies
}

Mohammad R. Hamidizadeh, Ph.D., Shahid Beheshti University, Iran Mohammad E. Fadaeinejad, Ph.D., Shahid Beheshti University, Iran

\begin{abstract}
The range of techniques associated with competitive market structure has expanded rapidly since the inception of AI and ES in the 1980s. Schonberger (1986) integrated these techniques into the generic term world-class policies (WCF). The range and sophistication of these techniques place WCF status beyond the aspirations and competence of many financial institutes. In order to have sufficient level on FWCP, the related Knowledge could manage like the other capital assets KM appeared in this area. Knowledge management is as an open and a dynamic system that use different feedback loops and functions to update and promote the organizational knowledge. For the most part, knowledge management efforts have focused on developing new applications of financial information technology to support the capture, retrieval, and distribution of explicit and implicit knowledge. The paper explores how the concept of knowledge management can be relevant to FWCP decisions, through eighteen case studies based on small to large sized financial institutes experiencing both rapid growth and increasing international competition. The result of this pilot study indicates that the major obstacle to implementing a FWCP decisions is the lack of expertise or resources in conducting the lack of employees' understanding, education and training in carrying out the process.
\end{abstract}

Keywords: Financial Policy, Financial Strategy, Financial Knowledge Management, The Financial World-Class Policies

\section{INTRODUCTION}

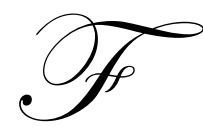

WCP decisions define as the pattern of human habits, beliefs and behavior concerning quality of financial decisions. FWCP decisions enable management systems implement and maintain effectively. A FWCP decisions is to provide data that reflects the existing decisions profile of a financial organization, and it provides an excellent foundation for a Management System successfully with the total involvement and dedication of each individual who is in any way a part of the services or processes. FWCP is more than just a technique and can more accurately be described as the methodologies management, JIT policy making and soon is best described as a philosophy of management that strives for simplicity, minimal lead time, and valueadding functions throughout processes. Knowledge Management is not a new issue, but it is newly practiced effectively especially in the last few decades (Malone, 2002). Increasing pressures on firms due to the uncertainty and dynamics of business environment, development of the knowledge economy, rapid advance in technology, increasing number of competitors and decreasing services lifecycles, make firms difficult to survive (Nonaka and Takeuchi, 1995). In addition, knowledge as a distinct factor of thought has an increasing awareness with increasing marginal return to scale (Koh, 2000). The firms which give importance capability to knowledge as a critical asset, create knowledge, deploy it within the organization well, and apply it into the policies properly will be successful and gain competitive advantage via differentiating (Nonaka and Takeuchi 1995). KM is crucial. KM skills are a central concern for corporate excellent universities and management schools. (Skerritt, 2005).

In this manner, a product (goods/service) is the reflection of knowledge or a set of knowledge used to obtain this product (Dincmen, 2003). Thus, introducing FWCP involves changing attitudes, beliefs and analysis. The finance industry generally has lagged behind other industries in implementing FWCP. 
Lohrke, Dolezal, and Reynolds (1999) emphasized on analytical laboratory to get world-class distinction with world-wide connection; from managing instrumentation to managing knowledge. They used virtual laboratory and emphasized the laboratory knowledge workers, the customers, and the virtual laboratory sites and product development centers. $\mathrm{Ng}$ and $\mathrm{Li}$ (2003) developed the financial model based on Hendricks. They examined its suitability for relationship of organizational knowledge management with information and communication technology (ICT). This study proposed that the impact of different organizational structures on knowledge management systems should be collectivity considered. The study improved the weakness of Hendricks' model.

It is very rare that a FWCP conducted on a finance site. The data obtained from a FWCP provides the decision profile of an organization. This helps the management identify the nature and extent of any decision divide that may exist and what that divide could mean in terms of working together. The aims is to discover how people in an organization work together and what motivates them. FWCP may also help assess the degree of success of the implemented on a finance site and effective cultural change is the secret to implementing FWCP successfully. Based on Nonaka and Takeuchi classification (1995), explicit knowledge is codified, ready to use and formatted on a graphics, documents and computer programs, etc. However, tacit Knowledge is implicit one. It could obtain from people's experience and intuitions. In this study, explicit knowledge firstly considers for design purposes and its approach used in order to develop the road map for the financial design of explicit FWCP system. The purpose of this paper is to report developing a questionnaire of FWCP decisions and then conducting a pilot for three financial organizations to study the feasibility of FWCP decisions in the finance site. From the result of the pilot study could find the difficulties encountered in a FWCP culture.

\section{THE CONCEPTS OF WCM AND KNOWLEDGE MANAGEMENT}

Schonberger (1986) coined the term "World Class Manufacturing" to cover the many techniques and technologies designed to enable a company to match its best competitors. What is readily apparent from the literature is that the concepts have developed principally in relation to the needs of larger scale manufacturers. Relatively little attention has been paid to the needs of the knowledge management and there exists scope for framing the ideas implicit in WCM for seeking to improve its competitive position. It is not sufficient, however, to attempt to apply techniques appropriate to financial organizations. The techniques covered by WCM made recognizable and relevant to financial organizations. If there is any possibility of them, FWCP decisions could adopted. When Schonberger (1986) first introduced the concept of WCM into popular parlance, the term has seen to embrace the techniques and factors. However, techniques of competitive manufacturing have well established before 1986. It would include statistical process control as one of the early manifestations. The substantial increase in techniques related in part to the growing influence of the manufacturing philosophies and economic success of Japanese manufacturers from the 1960s onwards. What is particularly interesting from a review of the literature, is that while there is a degree of overlap in some of the techniques, it is clear that relative to the elements that were seen as constituting WCM in 1986, the term has evolved considerably. In recent years, it has expanded most notably to include simultaneous engineering, bench marking and increasing emphasis on issues relating to manufacturing strategy. Clearly, the management of a company seeking world class level for its status would appear to be faced with a far more complex task than was the case previously.

The easiest way to acquire knowledge is to buy it, in other words, to buy the organizations, which own it or to recruit the people who know (Davenport and Prusak, 1998). This is showed that, today, the intellectual capital of an organization has become one of its most valuable asset. Knowledge management, defined as the art of creating and adding value by exploiting intellectual capital, focuses on the management of knowledge processes like searching, organizing, storing, using, sharing, developing and recording knowledge (Dinçmen, 2003). Knowledge processes become important especially when there is a need for assuring that right knowledge used by the right person in the right sequence at the right time. In order to realize this, organizations should employ a systematic approach for handling the knowledge within the organization. In other words, the management of (external or internal) knowledge could carry out in adherence to a previously defined methodology applicable to the organization in question (Aksoy and Oztemel, 2001). The purpose for managing diverse and distributed collections of organizational knowledge should consider enabling greater flexibility, sharing and openness in the use of the knowledge and in supporting an overall learning organization environment. The relationship between users of the knowledge, effective access to all sources of knowledge, and the organizational values and decisions could considered in developing an applicable and acceptable methodology (Ashdown and Smith, 1999). 
The "road-map" for KM implementation requires the conversion of organizational goals into implemental tactics. There are various methodologies to aid this process; the one is as "G-spot". The term G-spot stands for "Goals - Strategies - Plans - Objectives - and - Tactics (Shankar et el., 2003).

\section{OPERATIONAL KNOWLEDGE MANAGEMENT FOR FWCP}

Knowledge management entails helping people share and put knowledge into action by creating access, context, infrastructure, and simultaneously reducing learning cycles (Massey et al., 2001). In order to have sufficient level on knowledge management, a company must optimize its technology and organizational structure (Bhatt, 2001). Operational knowledge management concerns on daily activities around knowledge management principles. It focuses on sharing, disseminating information through all levels of organization. The important issue is to combine people and system integration (Zack, 1999). Financial knowledge management consists of gathering data, transform it to information and deploy through organization. In order to have better decision-making process, a company must capable of services transactions.

Organizations initiating an intensive program FWCP naturally want to increase the efficiency of the methodology while deploying it all through the organization. In line with this, they need an infrastructure in order to acquire the training capability and to maximize return on investment by sharing policies projects. Organizations, which usually make costly consultancy investments in order to initiate the program, need to define organizational roles and responsibilities, design training curriculum, and manage projects systematically for customizing and internalizing the approach. In order to sustain the achievements and to align the program with the corporate decisions culture practitioners have pursued a systematic approach, its consequence researchers have made various research where they list critical success factors of a successful FWCP. With these in mind, it is decided to use axiomatic design, a design methodology, which is also adopted by FWCP, especially to design a new methodology where critical success factors will be considered in such a way that their relations and sequences will be clear for the practitioners. Elements of knowledge management have mentioned in various studies on WC site (Harry, 2001). However, it would be an enhancing study to consider knowledge management and WCP together within a systematic approach like axiomatic design. The use of axiomatic design for designing a methodology about a successful WCP also makes it easier to consider knowledge management principles in order to maximize the benefit of the program.

In our cases, there was a clear emphasis on the use of global general information technology tools to support KM activities different solutions are appropriate and organizations need to find the solution that is right for their context. There is arranging of approaches that can be takes in considering technology to assist KM, as reported here on Table 1.

Table1: Use of IT in KM for World Class Organizations

\begin{tabular}{|c|c|c|c|c|c|c|c|c|c|c|c|c|c|c|}
\hline 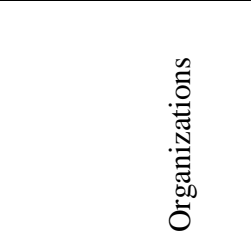 & 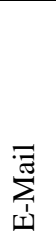 & 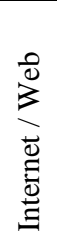 & 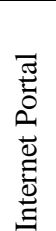 & 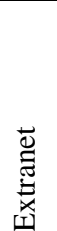 & 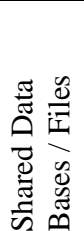 & 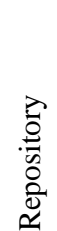 & 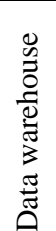 & 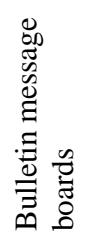 & $\begin{array}{l}\tilde{p} \\
\underline{v}\end{array}$ & 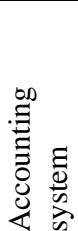 & 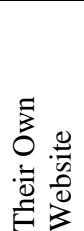 & $\stackrel{\tilde{z}}{\Sigma}$ & $\begin{array}{l}\text { 庶 } \\
0\end{array}$ & 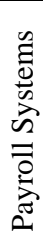 \\
\hline Restaurant & $\mathrm{C}$ & $\overrightarrow{\mathrm{C}}$ & $\bar{C}$ & & $\mathrm{C}$ & $\mathrm{C}$ & $\mathrm{C}$ & & & $\mathrm{C}$ & & $\mathrm{C}$ & $\mathrm{F}$ & $\mathrm{C}$ \\
\hline Police & $\mathrm{C}$ & $\mathrm{C}$ & $\mathrm{C}$ & & $\mathrm{C}$ & & & & & $\mathrm{F}$ & $F$ & & & \\
\hline Designers & $\mathrm{C}$ & & $\mathrm{F}$ & $\mathrm{F}$ & $\mathrm{F}$ & & & & & & & $\mathrm{F}$ & & \\
\hline High Tech Manuf. & $\mathrm{C}$ & $\mathrm{C}$ & $\mathrm{C}$ & & $\mathrm{C}$ & & & $\mathrm{C}$ & & & & & & \\
\hline Consult & $\mathrm{C}$ & $\mathrm{C}$ & $\mathrm{C}$ & & $\mathrm{C}$ & $\mathrm{F}$ & & $\mathrm{F}$ & & & & & & \\
\hline B2B Service & $\mathrm{C}$ & $\mathrm{F}$ & $\mathrm{F}$ & & $\mathrm{C}$ & & $\mathrm{F}$ & & & $\mathrm{C}$ & & & & \\
\hline$R \& D$ & $\mathrm{C}$ & $\mathrm{C}$ & $\mathrm{C}$ & & $\mathrm{F}$ & $\mathrm{F}$ & & $\mathrm{C}$ & & & & & & \\
\hline Housing & $\mathrm{C}$ & $\mathrm{F}$ & $\mathrm{C}$ & & $\mathrm{C}$ & $\mathrm{F}$ & & & & & $\mathrm{C}$ & & & \\
\hline Manuf. Ind. Prod. & $\mathrm{C}$ & & & & $\mathrm{C}$ & & & & & & & & & \\
\hline Consumer Prof. & $\mathrm{C}$ & & & & $\mathrm{C}$ & $\bar{F}$ & & & & & & & & \\
\hline
\end{tabular}

(C) Means current systems \& (F) means suggested future.

Source: Edwards, Shaw \& Collier, 2005. 


\section{DECISIONS AND PHILOSOPHY IN FWCP}

FWCP decisions are a collectively term that comprises of a whole set of implicit, widely shared beliefs, traditions, guidelines, values and expectations that characterizes a group of people which is a way of life handed down from one generation to the next. FWCP seems to affect almost every aspect of policymaking. Knowledge processes become important especially when there is a need for assuring that right knowledge used by the right person in the right sequence at the right time. In order to realize this, organizations should employ a systemic approach for handling the knowledge within the organization. In other words, the management of (external or internal) knowledge could carry out in adherence to a previously defined methodology applicable to the organization in question (Aksoy and Oztemel, 2001). Outlined four specific attributes should always be included in FWCP implementations, a new approach to quality of decisions, JIT policies techniques, changes in management of the teamwork, and flexible approaches to meeting critical situation needs. Others consider decision as how things did habitually in an organization with the prevailing attitudes and the grown up pattern of a human behavior (Drennan 1992). It is inevitable that the society has been highly affected by the FWCP decisions. According to Watson (1994), FWCP decisions provide guidelines for financial actions and resources to help us shape and justify actions for the best of our needs and interests. The principles that he taught shaped the entire governmental administrative system.

\section{A FRAMEWORK FOR ACTION}

Knowledge is a vital global asset. Little wonder then that the "Corporate World-class University" (CWCU) has evolved with rapid socio-economic and technical change in the workplace and in a global environment. (Skerritt, 2005).

Most research in knowledge management has focused on "hard" methodologies for developing data and the information processing of knowledge technologies (McElroy, 2003).

"Soft" methodologies for development human and social capabilities, including personal knowledge, have largely overlooked. Our "soft-hard methodology" model of action world-class learning and global action research (AWCLGAR) helps us to access, communicate and manage organizational and personal knowledge, to develop expertise's innovative, and creative capabilities, and to emancipate these expertise from the shack of positivism into a weighted balance positivist paradigm of research, development and self-knowledge. Figure 1 is a typical model of the values, strategies, and techniques in an AWCLGAR decisions and of the matching actions, applications, and cases of AWCLGAR programmers.

As we have considered in figure 1, we can distinguish KM contributions, Knowledge successes processes, and manufacturing processes, and Knowledge contribution may viewed in terms of financial world-class policies framework. FWCP processes produce knowledge that used in the other financial processes of the institute. These, in turn, produce financial results.

\section{CASE STUDIES}

A key aspect of testing the concepts developed in the research programmer has been the collaboration of several institutes. A brief comparison made between two them. Company A is a contract stock exchange. It transactions worth several million dollars a year and has doubled in size on an almost annual basis over the ten years or so of its existence, so that it has about 49 employees at present. It employed the groups of senior managers from the outset who were experienced in the financial market and who could attract sufficient capital to enable the company to invest in advanced transactions stocks. The nature of their market is such that an institute has to be World Class however large, or small it is. Consequently, institute A has not just invested in the most advanced markets, but in training for its employees, in a management information system, in produce development and in a plan of continuous improvement that (independently) parallels the Gap Analysis outlined above. Company A has the clear objective of maintaining rapid growth so that it can seek a listing on the London Stock Exchange. Company B, although in stock exchange, does not have the capital resources to invest in the latest high transactions. Its business focused on the design of printed Treasury bond and on the activity of Treasury bill. Most of the institute's capital tied up in working capital so that growth is limited to organic growth derived from profits. The 
institute is seeking to broaden its institute base to reduce its dependence on particular contracts. This dependence has illustrated in dramatic form recently, as a drop in orders has led to a reduction in the size of the workforce of almost $50 \%$. The institute is not able to fund the stocks necessary to meet current legislative requirements for new market, so service development has ceased. The institute competes on the price for a given volume of order combined with speed of response. Its management is unaware of the concepts included in the term financial World Class policies, but it is acutely aware of the need to reduce costs whilst maintaining quality and speed of response. It is medium enough, at 53 employees to enjoy good communications internally and to be able to implement Gap Analysis in its production and material control functions.

Figure 1 shows a model of AWCLGAR reflection and successes for world class knowledge management.

Figure 1: a model of AWCLGAR reflection and successes for world class knowledge management

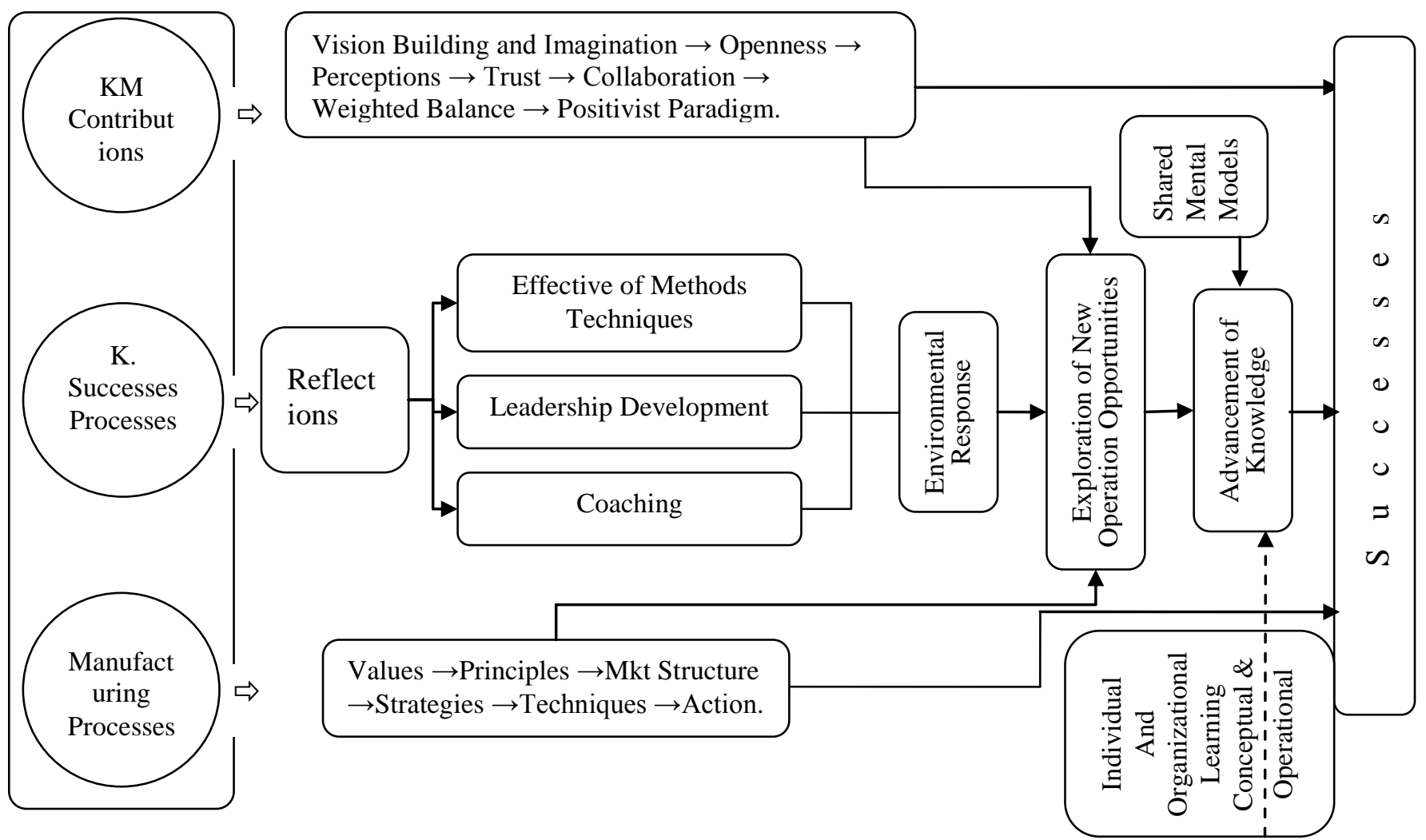

Source: Firetone \& McElroy, 2003; Mcelroy, 2003; and Skerritt, 2005.

Company A, whose business is a contract stock exchange, epitomizes in many respects the type of SME involved in the research and its growth based on the framework put forward by Robinson et al (1984). Having starting on a small scale, the company quickly gained a reputation for innovation, design and enjoyed steady sales growth, to the point where it presently has a turnover of some 12 million dollar per annum and has over 49 employees. The institute's leader of the contract stock exchange has enjoyed increased sales through successful innovations in a services domain; it has invested relatively little in changing existing transaction techniques. Increased services volumes dealt with simply by scaling up existing method without a strategic overview of whether it was using the most efficient technologies available. Although this approach has held the institute in good stead, there is a growing appreciation among the management that while its services range and marketing is "world class" it needs to develop an equally effective "world class" policy strategy, particularly in the face of growing international competition. The challenge facing the management is to determine what actually constitutes "world class" in their particular business. 
Table 2: Performance levels required to attain WC Status

\begin{tabular}{|l|l|l|}
\hline \multicolumn{1}{|c|}{ Attribute } & Existing Transaction Performance & \multicolumn{1}{c|}{ Criteria For World Class Services } \\
\hline Market Share & $40 \%$ Marketplace & $\begin{array}{l}\text { Retain 40\% Of Marketplace } \\
\text { Plus Increased Overseas Sales }\end{array}$ \\
\hline Lead Time & Between 2 To 3 Weeks & Less Than 1 Week \\
\hline Set Up Time & Hours & Minutes \\
\hline Strategy & $\begin{array}{l}\text { No Link Between Service Strategy And } \\
\text { Market Strategy }\end{array}$ & $\begin{array}{l}\text { Simultaneous Between Market And } \\
\text { Services Strategy }\end{array}$ \\
\hline Service Emphasis & Push System Based On Forecasting & Pull System Of Customer Order \\
\hline Training & Minimal Training Of People & Continuous Training Of People \\
\hline Batch Size/Lot Size & 20 & Lot Size Of One \\
\hline Number Of Suppliers & 10 & 5 \\
\hline Preventive Maintenance & Non-Existent & Planned Maintenance \\
\hline $\begin{array}{l}\text { Communication Between Stores And } \\
\text { Assembly }\end{array}$ & Very Weak & Part Of Established Work Practices \\
\hline Customer Response & Reasonable & Customer Driven Business \\
\hline WIP, Inventory & $\begin{array}{l}\text { Vast Amount : Average Inventory For } \\
5-6 \text { Weeks Services And A Lot Of WIP }\end{array}$ & $\begin{array}{l}\text { Small Inventory, WIP Hours Or Days } \\
\text { Not Weeks }\end{array}$ \\
\hline Product And Process Designed & Linear Manner & Simultaneously \\
\hline Relationship With Suppliers & Short Term & $\begin{array}{l}\text { Close, Long Term Relationship With } \\
\text { Suppliers }\end{array}$ \\
\hline Cost Of policy & $10 \%$ Plus Of Sales & Less Than 1\% Of Sales \\
\hline
\end{tabular}

\section{QUESTIONNAIRE FOR FWCP}

In designing the questionnaire, references made to:

(1) Group $X_{1}$ of institutes (2007) proposed six characteristics of FWCP decisions

(2) Group $X_{2}$ of institutes (2007) proposed five values for creating FWCP decisions

(3) Group $\mathrm{X}_{3}$ of institutes (2007) proposed four-step FWCP decisions process.

Group $\mathrm{X}_{1}(2007)$ the six characteristics are:

(1) Open and continual communication

(2) Supportive internal partnerships

(3) Teamwork approach to problems

(4) Obsession with continual improvement

(5) Broad-based employee involvement and empowerment

(6) Sincere desire for customer input and feedback

Group $\mathrm{X}_{2}$ (2007) the five values are:

(1) Focus on customer satisfaction,

(2) Focus on processes and their continual improvement

(3) Focus on teamwork and cooperation

(4) Focus on openness and sharing of information

(5) Focus on the use of scientifically derived data for making decisions

Group $X_{3}$ (2007) The four-step culture audit process proposed includes:

(1) Undertaking a culture

(2) Identifying current values

(3) Developing organizational and human resource management strategies

(4) Measuring performance

There are six headings in the questionnaire including:

(1) Communication opportunity between management and employees 
Trust and free flow of opinions among staffs

Teamwork spirit in the organization

Staff commitment and involvement

Customer relationship and customer satisfaction

Focus on continual improvement

Each of the above headings contains seven to twelve questions. There are altogether fifty-one questions in the questionnaire. Due to lacking of space, it is impossible to show all the questions in this paper. Only the questions under the heading of, say, (5) customer relationship and customer satisfaction showed in the Appendix at the end of this paper for readers' reference. It can be saw that in each heading of the questionnaire there are two parts of questions, Part A and Part B. Due to the limited space available for writing this paper, only Part A's analysis showed and discussed. Altogether employees from eighteen institutes of three different Group (six large, six medium and six small) were interviewed - fifteen employees from each institutes. The fifteen from each institute were of different levels in order that different points of view and opinions obtained. They were Director manager, Middle manager and Strategic manager. The following section reports the findings.

\section{FINDINGS AND OBSERVATIONS}

Table 1 shown below summarizes the findings. Each of the scores shown is the sum of the scores of individual questions for each of the six headings.

Table 3: total scores obtained by different interviewees

\begin{tabular}{|l|l|c|c|c|c|c|c|}
\hline \multicolumn{2}{|c}{ Six headings } & $\mathbf{1}$ & $\mathbf{2}$ & $\mathbf{3}$ & $\mathbf{4}$ & $\mathbf{5}$ & $\mathbf{6}$ \\
\hline \multirow{3}{*}{ Large Group } & Director manager & 81 & 85 & 81 & 85 & 85 & 85 \\
\cline { 2 - 8 } & middle manager & 71 & 82 & 80 & 80 & 81 & 80 \\
\cline { 2 - 8 } & Strategic manager & 85 & 68 & 70 & 69 & 87 & 66 \\
\hline \multirow{3}{*}{ Sedium Group } & Director manager & 83 & 82 & 84 & 83 & 89 & 81 \\
\cline { 2 - 8 } & middle manager & 70 & 74 & 67 & 69 & 87 & 69 \\
\cline { 2 - 8 } & Strategic manager & 66 & 68 & 65 & 70 & 87 & 82 \\
\hline & Director manager & 83 & 69 & 82 & 84 & 81 & 68 \\
\cline { 2 - 8 } & middle manager & 67 & 85 & 73 & 68 & 66 & 82 \\
\cline { 2 - 8 } & Strategic manager & 67 & 86 & 62 & 72 & 66 & 68 \\
\hline
\end{tabular}

\section{INTERVIEWEES' PERCEPTION IN CONDUCTING A FWCP}

In the current study, three group employees, namely, director manager, middle manager and strategic manager had selected to interviewee and questions asked directly by the authors during the interviews. As a result, the interviewees fully understood the questions asked and no misunderstanding experienced. An institute-wide survey be conducted, special attention has to be paid in designing the questionnaire in order to allow for the different backgrounds of respondents. A institute office usually comprises of staff with widely differing educational and training backgrounds. Their roles and responsibilities in the institute were also quite different. Therefore, in designing the questionnaire targeted for such a group, the questions asked should closely relate to their routine duties so that meaningful results to obtain. Moreover, the wordings used should be appropriate to the respondent's background as to improve the understandability of the questions. The average duration of each interview was around an hour. To obtain in-depth assessment of the current quality culture status of a institute, detailed questions such the one used in this pilot study was appropriate. However, since FWCP decisions are a collective belief of a group of people in order to conduct a FWCP for an institute. From the authors' point of view, the FWCP manager from the head office should be the most suitable person to conduct a FWCP for the following reasons:

a) Managers can understand all WC requirements.

b) Managers had conducted regular WC enables the managers to monitor the overall status of WC decisions of the institute.

c) Managers should be in the best position to analyze results obtained from WC. 


\section{How can an world-class organization's decisions be changed to encourage knowledge sharing?}

It is a challenge for all world-class organizations to enhance effective knowledge creation within and between different knowledge domains and other communities of practices.

The transfer system needs appropriately use the following steps.

1. To formulate a guide to words the institute's knowledge vision.

2. Absorb capacity. A team or individual must already have enough related knowledge to absorb the new knowledge.

3. Prepare a catalyst to knowledge creation.

4. $\quad$ Link sharing knowledge to widely held core values.

5. $\quad$ Fit the kind of knowledge and tacit one intended.

6. Enhance the networks that already exist. Enable them with tools, resources and legitimization.

7. Formulate the context, objectives and the type of complexity in the setting.

8. Changing and evolving the underlying values behind all of the actions, and the resulting behavior patterns.

9. Make a coordinate of knowledge creation initiatives.

10. Raise the level of trust between members in the institute.

11. Install an enabler of a sharing culture.

12. Draw on the different role of the knowledge facilitator.

13. Make a visible connection between sharing knowledge and practical business goals, problems and results.

14. Think how effective change happens in your institute.

15. Ask influential people and managers to encourage and even pressurize people to share their knowledge.

16. Build sharing knowledge into routine performance appraisal.

17. Build financial expert system based on artificial intelligence.

(Carpenter and Rudge, 2003; Roth, 2003; Marr et el., 2003; Nicolas, 2004; Hasen and Al-Hawari, 2003).

Figure 2: A causal model for promoting WCKM

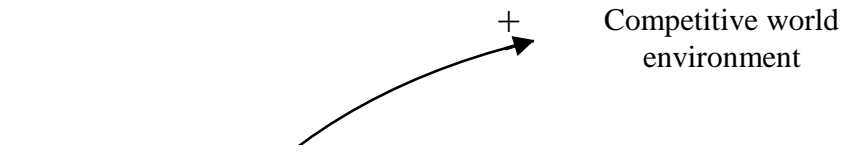

World-class capabilities

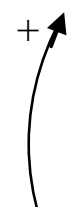

World-class decisions

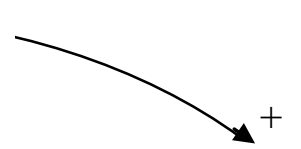

World-class knowledge mgt.

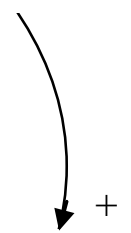

World-class financial mgt.

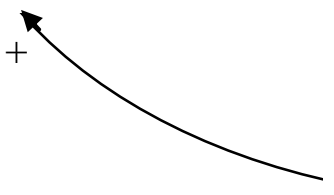

Policies diversification

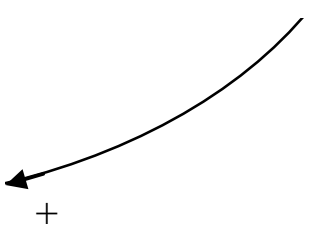




\section{CONCLUSION AND SUGGESTION FOR FURTHER WORKS}

While the concept of what constitutes FWCP has received considerable attention in the academic literature, it has developed principally in relation to the needs of larger scale financial institutes. Faced with a growing list of the elements needed for world -class manufacturing the management appears faced with a daunting task. Traditional factors of production, land, labor and capital - are becoming restraints rather than driving forces, whereas knowledge is becoming the critical factor of services (Stewart, 1997). An organization cannot function without knowledge. Focusing on the stock exchange operations in a knowledge management using the "gap analysis framework" has proved its utility in assisting the management to make progress towards a model of FWCP that is applicable to their circumstances. Based on this study, in order to understand a word class and WCKM, a causal model proposed as Figure 2.

In this study in order to understand a thorough decisions of a institute a WCP should be do more until different areas of improvement required are identified.

\section{AUTHOR INFORMATION}

Mohammad Reza Hamidizadeh, Associate Professor, Management \& Accounting, Shahid Beheshti University Eveen, Tehran, Iran.

Academic Degrees: B.B.A.1977, Tehran University, M.B.A, 1980, State University Of Mississippi., U.S.A., Ph.D., 1994, Management, Major Field: O.R., Tehran University.

Academic Activities: For Undergraduate, Graduate, And Post Graduate School from 1981 up to now: Statistics, Econ., D.M. \& O.R., System Dynamics, Strategic Management, Advanced Operations Research, Advanced Marketing Research.

Books \& Article: 10 Books \& 38 Articles.

Mohammad Esmaeil Fadaeinejad, Faculty of Management \& Accounting, Shahid Beheshti University, Eveen, Tehran, Iran.

Education: Ph.D. University of Tehran, Iran, 1994, Finance, MBA University of Oklahoma, USA, 1975, Finance, B.A. College of Accounting, Iran, 1973, Accounting.

Professional Experience: 1980 - Present, Shahid Beheshti University - Tehran, 1980 - 1990, Instructor of Managerial Finance, 1990 - 2000, Assistant Professor, 2000 - Present, associate Professor.

Academic Administration: Dean of Faculty, 2000 - 2009, Associate Dean for Graduate Studies, 1990 - 1996, Head of Finance Department, 1986 - 1990.

Books \& Article: 3 Books \& 23 Articles.

\section{REFERENCES}

1. Carpenter, S. and Rudge, S. (2003), “A Self-Help Approach to Knowledge Management Benchmarking”, Journal of Knowledge Management, Vol. 7, No. 5, Pp. 82-95.

2. Dincmen, (1998), "The Model of Philosophy of Management", Journal of Production of Operations Management, Vol. 17, No. 12, Pp. 71-80.

3. Edwards, J.S; Shaw, D. and Collier P.M. (2005), "Knowledge Management Systems: Finding a way with Technology", Journal of Knowledge Management, Vol. 9, No. 1, Pp. 113-125.

4. Firestone, J.M. and McElroy, M.W. (2003), Key Issues in the new Knowledge Management, B-H, London.

5. Gourieroux, C\& J.Jasiak(2001) Financial Econometrics, New Jersey: Princeton University Press.

6. Lohrke, C.T.; H.Dolezal, and S.L. Reynolds (1999), "Analytical laboratory: World class Distinction with World-wide Connection; from Managing Instrumentation to managing Knowledge", Laboratory Automation and Information Management, Vol. 34, Pp. 41-49.

7. Malone, N. (2002) Knowledge management and Organization, McGraw-Hill, New York

8. Marr, Bernard; Gupta, O., Pike, S. and Roos, G. (2003), "Intellectual Capital and Knowledge Management Effectiveness", Management Decision, Vol. 41, No. 8, Pp. 771-781.

9. Massingham, Peter (2004), "Linking Business Level Strategy with Activities and Knowledge Activities and Knowledge Resources", Journal of Knowledge Management, Vol. 8, No. 6, Pp. 50-62. 
10. McElroy, M.W. (2003), The New Knowledge Management: Complexity, Learning and Sustainable Innovation, Butter Worth Heinemann, London.

11. Ng, Jemmy J.M. and K.X. Li (2003), "Implication of ICT for Knowledge Management in Globalization", Information Management and Computer Security, Vol. 11, No. 4, Pp. 167-174.

12. Nicolas, Rolland (2004), “Knowledge Management Impacts on Decision Making Process", Journal of Knowledge Management, Vol. 8, No. 1, Pp. 20-31.

13. Nonaka and Takeuchi, (2000) "The Role of Knowledge Management in the Business", Journal of Knowledge management, Vol. 29, No. 6, Pp. 212-218.

14. Roth, Jonas (2003), "Enabling Knowledge Creation: Learning from an R \& D Organization”, Journal of Knowledge Management, Vol. 7, No. 1, Pp. 32-48.

15. Schonberger, R. J., (1986) “World-Class Manufacturing”, the Lessons of Simplicity Applied, MacMillan, New York.

16. Shankar, R.: Singh, M.D.; Gupta, A. and Marain, R. (2003), "Strategic Planning for Knowledge Management Implementation in Engineering Firms", Work Study, Vol. 52, No. 4, Pp. 190-200.

17. Skerritt, O.Z. (2005), "A Model of Values and Actions for Personal Knowledge Management”, Journal of Workplace Learning, Vol., 17, No. 112, Pp. 49-64. 